damping capacity of concrete; concrete strength testing; problems associated with excessively high water/cement ratios; high-strength concrete; fineness of cement; methods of measuring workability. The section on research on the design of structures is noteworthy for its treatment of model testing of structures such as bridges (Manchester Skyway Bridge) and buildings (Metropolitan Cathedral at Liverpool). A further section of the report deals with research on methods of construction. In this connexion: "One of the most interesting experiments recorded ... is the construction of a length of $B 6247$ in Lancashire as a trial to examine the effects of the omission of expansion joints. Observations and measurements on this project are continuing, but early results suggest that the development of stress in tho concrete indicates little difference between sections with and without expansion joints".

The section of the report on information services provided by the Association is fully comprehensive. These include: education; library facilities; publications; liaison with Press, radio and television; films; exhibitions; organized visits; lectures and discussion meetings. In the matter of library facilities, there has been recently issued a Catalogue of Publications of the Cement and Concrete Association currently available for Distribution in the United Kingdom $\uparrow$. This is an informative and valuable publication and should be in the possossion of all concerned with the Association's literature on cement and concrete. It lists the following titles (among others): advisory booklets and leaflets; prestressed concrete; roads and road bridges; concrete as a material; technical memoranda; library abstracts; translations; Cement and Concrete Association reprints; bound volumes (for sale); research reports. Many of these publications are available for free distribution; those to be purchased are clearly so marked.
Recently, there has also been published an important booklet entitled The Flexural Strength of Plain Concrete: Its Measurement and Use in Designing Concrete Mixes, by P. J. F. Wright $\ddagger$. Fundamentally the thesis here presented is that usually the quality of concrete is judged by its crushing strength, less attention being directed to the functions of tensile and flexural strength. Where failures in concrete roads occur, it is argued, these generally arise from tensile stresses. A critical examination of the flexural strength of concrete has accordingly been made, based on a great deal of small- and large-scale experimental work. Writing in the foreword to this publication, Sir William Glanville, director of road research. says: "A study was first mado of methods of testing. This led to the introduction of a British Standard method for flexural testing. Using this standard test, the strength of a range of concrete mixes was investigated. The type of aggregate proved to be important. A section of the paper describes the way in which the data obtained may be used in designing concrete mixes and compares mixes based on compressive and flexural strength requirements". It is pointed out that the use of flexural strength of concrete for specification and control purposes has not as yet been widely adopted in road construction in Britain, but there is little doubt that the data recorded in this paper will be closely examined by highway engineers and others concerned with design and durability, and failures, of concrete roads.

H. B. Milner

$\dagger$ Catalogue of Publications of the Cement and Concrete Association currently available for Distribution in the United Kingdom. Pp. 40. (London: Cement and Concrete Association, 1964.)

$\ddagger$ Department of Scientific and Industrial Research: Road Researcl Iaboratory. Road Research Technical Paper No. 67: The Flexural Strength of Plain Concrete-Its Measurement and Use in Designing Concrete Mixes. 4s. 6 d. net.

\title{
SONIC INVESTIGATIONS ON INTERNAL DAMPING IN SOLIDS
}

\begin{abstract}
A SYMPOSIUM entitled "Sonic Investigation on Internal Damping in Solids" was held at Imperial College, South Kensington, during August 6-8, 1964. It was organized by the Acoustics Group of the Institute of Physics and the Physical Society, and sixteen speakers contributed papers.

It is some thirteen years since the last symposium on this subject was organized jointly by the Physical Society and the Institute of Metals. The gap of thirteen years, far from representing lack of interest in the subject, rather indicates that papers concerning it are often relevant in other contexts. For example, the International Conference ${ }^{2}$ on Crystal Lattice Defects, held in Tokyo in 1962, included suventeen papers on internal damping. In the present symposium, besides measuring techniques, such matters as the influence of third-order elastic constants on apparent internal damping, the effects of microcracks and structural changes on the damping of ceramics and the choice of rubbers for highly efficient shock absorbers were discussed.

In the thirteen years since the last internal damping conference in London, interest has widened in non-metals like quartz, spinels and sapphire, in polymers, and in semiconductors, which at that time wero academic curiositios. At that time the role of dislocations in internal damping was only beginning to be understood although it was predicted at that meeting that such damping should possess strongly directional properties and experiment has since verified this. At that time, too, little had been done with frequencies over $20 \mathrm{Mc} / \mathrm{s}$, but now frequencies of $70,000 \mathrm{Mc} / \mathrm{s}$ have been used in damping work. These high-frequency waves can now propagate because of the modern development of crystals of very high purity and perfection, such as silicon, germanium and sapphire,
\end{abstract}

which possess so few irregularities that little scattering occurs (except from thermal phonons) even with wavelengths as small as $800 \AA$. Moreover, in modern highpurity metals, the mean freo path of the electrons may be comparable with that of ultrasonic wave-lengths, so that interaction can occur and Formi surfaces can be delineated. Phonon-phonon interaction, and the interaction of waves with nuclear spin and with electron spin. have only been investigated within the past dozen years. Another development of great potential importance concerns semi-conductors, such as cadmium sulphide, which also possess piezoelectric properties. In single crystals of this substance electrons can be mobilized either by an electric field or by bright light and can increase attenuation, often dramatically. When, however, the electron drift field velocity exceeds that of the ultrasonic waves. in place of attenuation, useful amplification of the ultrasonic wave can occur (see Fig. 47, p. 251, of ref. 8).

A broad outline of the subject was given in the introductory address by Dr. R. W. B. Stephens (Imperial College) and continued by Mr. G. Bradfield (National Physical Laboratory) with emphasis on experimental techniques covering a wide range of froquency, temperature and pressure - from $1 / 1,000 \mathrm{c} / \mathrm{s}$ to many megacycles. from absolute zero to $1,100^{\circ} \mathrm{C}$ and at pressures up to 1,000 bars. It was stressed that the techniques were diversified not only by these wide conditions but also because of the enormous spread of loss angle values from around unity down to $3 \times 10^{-8}$ so that an embarrassing variety of equipment is involved. Prof. J. F. W. Bell (Royal Naval College, Greenwich) described a magnetostrictive method of test which would give at least qualita tive information at temperatures as high as $2,300^{\circ} \mathrm{C}$ for both longitudinal and torsional modes. 
Internal friction becomes manifest in solids subjected to homogeneous cyclic stress, as in torsional pendulum devices, in standing wave phenomena (as in the resonance of rods or disks) and in travelling wave packets, wide in relation to a wave-length, which progress with only a slight divergence limited by diffraction effects. Joint friction between lumped elements limits accuracy in the first manifestation but, using the second, that is, resonance techniques, a useful degree of accuracy can be obtained even for $Q$ values ( $\pi /$ decrement) as high as 30 million or more, a value for a good crystal of silicon. With travelling waves, however, accuracy is difficult to obtain in such a material for modest frequencies up to, say, $100 \mathrm{Mc} / \mathrm{s}$, for relatively great corrections have to be made for the wave packet divergence and, because multiple end reflexions are used, further large corrections must be made for imperfect specimen-transducer joints and for mode changing at encounter with lateral boundaries. These difficulties (see also ref. 3) were discussed by Dr. M. Redwood (Queen Mary College) together with the consequences of practical imperfections in transmitting and receiving electronics; he also touched on the pulse broadening effects due to frequency-dependent internal damping.

Nevertheless, using these travelling wave techniques, relative values are often useful enough and, as Prof. $\mathbf{R}$. Truell pointed out, some of the difficulties soon disappear at higher frequencies, say, at 1,000 Mc/s where, even in single crystals, the attenuation per centimetre is several decibels so that specimens a few centimetres long are adequate. At these high frequencies $(c .4,000 \mathrm{Mc} / \mathrm{s})$ and low temperatures this attenuation constant starts off as a high power (c. 4) of the absolute temperature but only increases as a low power $\left(c . \frac{1}{2}\right)$ of the frequency.

\section{Waves in Heavily Absorbing Media}

Travelling waves, however, present considerable difficulties with high decrements, around 0.13 or more as in polymers and, for example, in polycrystalline lead. Prof. $H$. Kolsky (Brown University) described the propagation of a sharp pulse into a viscoelastic solid where both the phase velocity and the attenuation are highly frequencydependent. A pulse, initially very narrow, soon develops a characteristic shape which broadens linearly with range. He had found ${ }^{4,5}$ that waves in polycrystalline lead rods behave somewhat like this, but in these rods not only is the anelasticity frequency-dependent but the stressstrain relation is non-linear. In such materials, in general, the bulk modulus loss angle is only a fraction of the shear modulus loss angle. Prof. Kolsky pointed out that, besides the progressive wave shape change, when a sharp pulse encounters an interface between two bodies matched at one frequency but differing largely in the frequencydependence of their complex characteristic impedances, very curious wave shapes are reflected.

Mr. M. F. Markham (National Physical Laboratory) pointed out that geometrical path length corrections must be applied to the $\mathrm{Kono}^{6}$ method of measuring polymer internal damping, using travelling waves encountering a slab obliquely when immersed in a liquid. He agreed with Prof. Kolsky's separation of the real and imaginary parts of the bulk modulus $K^{\prime}, K^{\prime \prime}$ from the real and imaginary parts

$$
\left(K^{\prime}+4 / 3 G^{\prime}\right)+i\left(K^{\prime \prime}+4 / 3 G^{\prime \prime}\right)
$$

of the modulus involved in travelling longitudinal wave propagation, with the help of the corresponding rigidity modulus components $G^{\prime}$ and $G^{\prime \prime}$, derived from shear wave propagation. He supported Mr. G. Bradfield's suggestion that the partition of waves at interfaces when decrements were in the region of unity or more might have to be calculated by introducing complex characteristic impedances into the Knott equations. However, he avoided such difficulties by using two polymer samples of different thicknesses.

\section{Interaction with Conduction Electrons}

Dr. K. Mackinnon described measurements in which electron movement in metals caused absorption of the sound wave; frequencies from 10 to $500 \mathrm{Mc} / \mathrm{s}$ were used. In order to achieve adequate interaction the mean free path of the electrons must be of similar magnitude to the sonic wave-length. Single crystals of great purity (c. 2 p.p.m.) were used, and the experiments were made at low temperatures to avoid scatter from thermally-induced singularities. Two techniques were used, with and without a magnetic field. In the latter, because the Fermi velocity of the electrons is about 300 times the sound-wave velocity, only electrons moving nearly parallel with the sonic wave-front interacted. Much more interaction occurs using a magnetic field to cause the electrons to orbit with a diameter equal to an integral number of sonic wave-lengths for peak absorption. Thus these maxima appear at equal intervals in the value of the reciprocal field. The absolute value of the absorption need not be known. The orbit properties define the Fermi vector in $k$ space and adjustment of the attitude of the magnetic field vector relative to the crystal axes permits scanning of the Fermi surface and its delineation. Metals such as $\mathrm{Cu}, \mathrm{Ag}, \mathrm{Au}$ and Sn have been thoroughly examined and some features of the zine and cadmium? surfaces are also known. With H. V. Böhm, Dr. Mackin. non had investigated Landau levels in, for example, zinc. The ultrasonic method is often as convenient as the Haasvan Alpen magnetic susceptibility method for obtaining information concerning Fermi surfaces.

\section{Lattice Anharmonicity Effects}

Because the non-linearity of lattice forces is related to harmonic generation, and, via phonon-phonon interaction, to attenuation measurements, the extent of this nonlinearity can yield information on apparent internal damping. Mr. R. T. Smith (Imperial College) described his method of measurement of the travol times of shear and longitudinal waves passing transversely through a bar under axial compression. The changes in velocity were linearly related to this stress and permitted determination of these third-order elastic constants. For an isotropic polycrystalline solid, only three such constants were needed so that the variation of $c_{44}, c_{66}$ and $c_{22}$ sufficed.

Prof. R. Truell (Brown University), well known for his work on internal damping and wave propagation ${ }^{8}$, discussed ono of the most spectacular of modern sonic investigations concerning non-linearity of the lattice forces and its influence on the generation of a second harmonic wave. This can build up in amplitude linearly with range as the original wave travels along. The energy in this double-frequency wavo must be drawn from the fundamental wave and results in its attenuation, that is, there is apparent, but not necessarily real, internal damping. Indeed, it is possible that thermal loss does not necessarily occur. He described carefully designed electronics at $10-20 \mathrm{Mc} / \mathrm{s}$ which permitted the accurate measurement of this second harmonic production. Lattice anharmonicity results in thermal expansion because of thermal waves, and consequent static stress produces socond harmonics. Indeed, dislocations can give rise to second harmonics becauso of their stress fields. Thirdly, the presence of charge carriers can cause second harmonic generation in strongly illuminated materials with both photoolectric and piezoelectric properties, such as cadmium sulphide. In this, in single crystal form, the relativo attitudes of the sonic wave vector, the direction of the light and the crystallographic axes markedly influence attenuation. In discussion it was pointed out that subharmonic production was mathematically possible; it had not yet been sought experimentally. It had, however, been demonstrated that lattice anharmonicity could lead to bsams at sum and at differonco frequencies 
originating from the intersection of two strong sonic beams.

\section{Interaction with Charge Carriers in Piezoelectric Solids}

Dr. P. D. Southgate (Illinois Instituto of Technology) described other investigations on cadmium sulphide at about $225 \mathrm{Mc} / \mathrm{s}$ using a drift field to cause sonic wavo amplification. Ho had found that the mobility of charge carriors in it was much lessened by trapping mechanisms, about half of the carriers being affected. The presence of a travelling sonic wave could result in a drift fiold voltage, and noiso modulation could arise on the sonic wave due to the electronic processes which were occurring.

\section{Interaction with Dislocations}

Internal damping measurements offer information concerning the nature of dislocation movements, which may be stress-dependent or otherwise. This damping can be at loast partially explained in terms of the Granato and Lücke theory (ref. 8, p. 178), while the Bordoni peaks in f.c.o. solids behave broadly in accordance with the built-in kink theory of Brailsford (ref. 8, p. 207), a refinement of the theory of Mason, Sceger et al. The GranatoLücke theory was investigated in work reported by Mr. T. Hinton and Dr. J. G. Rider (Battersoa College of Technology), who made damping measurements on a series of lead-indium alloy single crystals (chiefly of $0.05,0.15$, 0.25 and 0.50 per cent In) and on lead-tin alloys, using longitudinal resonance at about $4 \mathrm{kc} / \mathrm{s}$ either at room temperaturo or at about $300^{\circ} \mathrm{C}$. Various strain amplitudes were used and the damping was separated into strain-dependent and strain-independent components. The former could be interpreted, over a limited range of composition, to vary as the fourth power, as predicted by the Granato-Lücke theory. The break-away stress on these f.c.c. alloys appears to be 5-100 times below that found by static tests. This is in line with the findings of Hasiguti et al. ${ }^{10}$ on b c.c. iron (see, for example, equation 23.11 of ref. 8). The solute-dislocation binding energy was four times that deduced from Cottrell's expression.

Dr. P. D. Southgate (Ilinois Institute of Technology) reported on an extension of his previous work ${ }^{8}$ on Bordoni peaks in hard crystals of silicon and of magnesium oxide. One set of crystals was cut as tuning forks (100 c/s $-600 \mathrm{c} / \mathrm{s}$ ) and another as bars (100 kc/s in longitudinal resonance). Dislocations were introduced systematically. With these two frequency ranges and damping data up to $1,400^{\circ} \mathrm{C}$, the activation energy of the silicon Bordoni processes was established as about $\mathrm{I} \cdot 6 \mathrm{eV}$. When the calculated core widths of the kinked dislocation were plotted for copper and silicon at various temperatures, normalized against melting point, silicon had only about a third of the core width of copper although the general shapes of the curves were similar. Comparing activation energies for silicon and indium antimonide, it was interesting to note that these were in the ratio of $2 \cdot 6$ which was roughly the ratio of their electron onergy gaps. Magnesium oxido behaved markedly differently from silicon, its decrement being distinctly dependent on strain amplitude. For this (and as found also by Hinton and Rider) the plot of $\log$ (strain $x$ decroment) as ordinate against reciprocal strain was not the straight line predicted by Granato and Lücke (see equation 22.1 of ref. 8) but was distinctly concave upwards. $\alpha$-Quartz is an example of a common single crystal tho damping of which has been examined up to $70,000 \mathrm{Mc} / \mathrm{s}$. It is suggested now that this damping is not primarily due to dislocations; much is due to phonon viscosity but some is contributed by ionic impurities trapped during growth. Natural crystals have remarkably uniform damping, but Dr. A. Seed (Standard Telephones and Cables, Ltd.) reported comparisons of synthetic crystals showing that the damping inoreased about ten-fold with doubling of growth-rate $\left(\frac{1}{8} \mathrm{~mm}\right.$ to
$1 \mathrm{~mm} /$ day). A large damping peak existed at about $60^{\circ} \mathrm{K}$ which was about 10 times smaller at the lower rate. It was much reduced by X-ray irradiation and was split into two $\left(c .30^{\circ} \mathrm{K}\right.$ and $\left.c .80^{\circ} \mathrm{K}\right)$ suggesting that paired ions were responsible. The magnitude was strain-independent. Working in the rango 5-100 Mc/s ho had established that in accordance with theory, damping should vary in the ratio of shear moduli for various cuts; the BT eut had about twice the damping of AT cut. At room temperature the decrement of both dropped roughly linearly with froquoncy (c. $10^{-6}$ at $10 \mathrm{Mc} / \mathrm{s}$ on $\mathrm{AT}$ eut).

Prof. Truell remarked that $\alpha$-quartz had far more damping than artificial sapphiro when tho latter is really pure. In discussion it was pointed out that though these were both trigonal crystals, the $c_{14}$ constant of quartz was proportionately greater and this cross-term might affect modo distribution and hence increase phononphonon interaction.

\section{Damping in Composite Bodies}

of less fundamental significance, though of great technological importance, were three papers by Dr. J. C. Snowdon, Mr. A. R. Payne and Dr. N. F. Astbury. Dr. Snowdon (Pennsylvania State University) had carefully analysed available damping and elasticity data on natura! and synthetic rubbers and allied polymers by the reduced variable method over temperatures mainly from $5^{\circ}$ to $35^{\circ} \mathrm{C}$, and at frequencies from 1 to $10,000 \mathrm{c} / \mathrm{s}$, and had applied this information in the first instance to the calculation of the efficacy of shock absorbers consisting, for example, of a mass supported by a rubber spring ${ }^{11}$. This exercise appears to show that the interaction between damping peak width and the inevitable relation of modulus drop to temperature imposed an upper limit on shock absorber efficacy whatever composition of rubber was tried; some slight improvements could be obtained with paralleled springs of differing composition, and with more complex mechanical structures. Mr. Payne (Natural Rubber Producers Research Association) reported on rubber damping and elasticity. He had found that, with a certain proportion of filler, such as carbon black, the damping was little affected by the nature of the rubber. Indeed, in certain circumstances, the rubber could be replaced by a paraffin liquid, the system retaining similar dynamic damping, and apparent elasticity and anelasticity, and some similarity of strain dependence. He thought, as did Dr. Snowdon, that the need was now not so much for new polymers for such things as tyres and shock absorbers, as for improved methods of dispersing filler in binder and achieving chemical bonding.

Dr. Astbury (British Ceramic Research Association) reported on work carried out at the British Ceramic Research Association ${ }^{12}$. The investigation of the sintering process covered widely different materials-brick, domestic and bone 'china', porcelain (including electrical insulation) and sintered alumina; the loss angles varied from 0.01 to $10^{-5}$. The damping varies nearly linearly with pore volume but is nearly invariant with frequency. One type of ceramic which is clay-based acts like a crystalline phase in a glassy phase with pores up to 20 per cent of volume; devitrified glass is similar but without the pores, and fine 'china' porcelain would be mainly vitreous with perhaps 5 per cent of closed pores. Thero secm to be fine cracks, especially around the pores, and those soem to be responsible for a great deal of the damping; structural changes occurring during damping-temperature runs, however, such as the $\alpha$ - $\beta$-cristobalite change at $100^{\circ}-$ $200^{\circ} \mathrm{C}$ and the $\alpha$-quartz change at c. $570^{\circ} \mathrm{C}$, are reflected in fluctuations in both damping and elasticity. In discussion it was suggested that the great volume change in the former might react with the micro-crack system to give damping poaks. An important problem concerns the desirability of internal damping in ceramics to reduce the risk of fracture from shock waves. 
In the symposium as a whole the damping of rocks to earthquake waves $(<1 \mathrm{c} / \mathrm{s})$ and to seismic exploration waves $(10-150 \mathrm{c} / \mathrm{s})$ was not discussed, and little was said about frequencies of $5,000 \mathrm{Mc} / \mathrm{s}$ and upwards. Little omerged in discussion concerning equipment design and techniques, although no doubt useful interchanges of information occurred privately. Littlo common ground is shared between workers on metals and hard single crystals on one hand, dealing with loss angles down to $3 \times 10^{-8}$, and workers on polymers dealing with loss angles of $0 \cdot 1-1 \cdot 2$ radians. Even so, an occasional symposium, in which such widely diverse fields of interest are included, serves a useful purpose. G. Bradfield

' Nature, 167, 1021 (1951).

${ }^{2}$ Proc. Symp. (1962). J. Phys. Soc., Japan, 18, Suppl. 1, 2,3 (1963).

${ }^{3}$ Redwood, M., Mechanical Waveguides (Pergamon Press, 1960).

- Bodner, S. R., and Kolsky, H., Proc. 3rd U.S. Nat. Cong. App. Mech.

(Amer. Soc. Mech. Eng.), 495 (1958).

${ }^{5}$ Kolsky, H., Stress Waves in Solids, first ed. (Clarendon Press, 1953).
${ }^{6}$ Kono, R., J. Phys. Soc., Japan, 15, 718 (1960); 16, 1580, 1792 (1961).

7 Daniel, M. R., and Mackinnon, K., Phil. Mag., 8, 537 (1963).

Truell, R, and Elbaum, C., in Handbuch der Physik, 11/2, edit. by Flügge, S. (Springer-Verlag, 1961).

'Southgate, P. D., Proc. Phys. Soc., B, 70, 804 (1957).

${ }^{10}$ Hasiguti, R. R., Igata, N., and Ueki, M., Acta Met., 12, 947 (1964).

${ }^{11}$ Snowdon, J. C., Rubberlike Materials, Their Internal Damping and Role in Vibration Isolation (Ordnance Research Laboratory, The Pennsylvania Vibration Isolation (Ordnance Research Laboratory, The P
State Univ., University Park, Penn., U.S.A., June 1964).

${ }^{12}$ Astbury, N. F., and Davis, W. R., Trans. Brit. Ceramic Soc., 68, 1 (1964).

OTHER REFERENCES ON INTERNAL FRICTION INCLUDE:

Mason, W. P., Physical Acoustics and the Properties of Solids (New York: Van Nostrand Co., 1958).

Mason, W. P., in Handbuch der Physik, 11/1, edit. by Flüggc, S. (Berlin: Son, W. P., in Handbuch

Entwistle, K. M., in The Physical Examination of Metals, edit. by Chalmer, B., and Quarrell, A. G., second ed. (London: Arnold, 1961).

Weertmann, J., J. App. Phys., 26, 202 (1955).

Nowick, A. S., in Progress in Metal Physics, edit. by Chalmers, B, 4 (London: Pergamon Press, 1953).

Zenar, C., Elasticity and Anelasticity of Metals (Chicago University Press, 1948).

\section{TENTATIVE CLASSIFICATION OF FOOD IRRADIATION PROCESSES WITH MICROBIOLOGICAL OBJECTIVES}

$\mathrm{W}^{\mathrm{s}}$ E were recently asked, as members of an expert group, to define the main types of irradiation process applied to foods for microbiological reasons, and to suggest names for the types recognized. This article briefly records our joint conclusions.

With any kind of process for the preservation of food, two different broad microbiological objectives can be distinguished. In the first, the aim is to kill all microorganisms of significance in the food, and, where achieved by heating, the process is commonly called sterilization, though a few micro-organisms may remain alive but quiescent; this is the condition well known to food technologists as 'commercial sterility'. For this type of heating process, the French have a special name appertization, commemorating Nicolas Appert, who invented it. The second broad objective is to kill many, but by no means all, of the micro-organisms. When achieved by heating, this is called pasteurization; it may be done either to kill pathogenic organisms in particular, or to reduce the number of viable micro-organisms generally and so improve keeping quality.

The same broad division of objectives applies to irradiation, so that hitherto radiation processes have commonly been separated, from the microbiological point of view, into radiation sterilization and radiation pasteurization. However, we did not regard this classification as adequate, or these terms as very suitable.

Sterilization is at best an abstract concept, which cannot be verified experimentally over any sizable number of packages, and special difficulties arise with an irradiation process. While viruses are comparatively easily killed by heat, such killing cannot be guaranteed with any process of irradiation alone, under conditions practicable with foods. Consequently sterilization, in the commonly understood sense of producing almost complete absence of viable micro-organisms, cannot be reliably achieved with radiation at present.

Pasteurization, again, is normally understood to kill most viruses, but this certainly cannot be achieved with the relevant doses of radiation. Moreover, as was pointed out at the European Meeting on the Microbiology of Irradiated Foods (F.A.O./I.A.M.S., Paris 1960 (ref. 1)), in the case of radiation treatment the term pasteurization is undesirably ambiguous, being used to describe processes with two distinct aims, one aim concerned with public health and the other not, which in some countries would require different legislative treatments. Even with heat processing, a different term is needed: for example, milk for cheese-making is sometimes heated to diminish its population of micro-organisms, but the heat treatment is less severe than that defined as pasteurization; the need for a term to describe this procedure has been plain for ten years, and was recognized by the International Dairy Federation, which provisionally proposed the word thermization.

We therefore suggest the following working definitions for the main types of irradiation treatment intended to kill micro-organisms in foods :

Sterilization by irradiation would be the application to foods of doses of ionizing radiation which produce sterility, that is, total absence of all viable micro-organisms as determined by any known method. This state cannot at present be guaranteed with any radiation process practicable with foods.

Among the attainable microbiological objectives, we recognized three types distinguished according to objective, and defined as follows:

Type $I$ is the application to foods of doses of ionizing radiation sufficient to reduce the number and/or activity of viable organisms to such an extent that very few, if any, are detectable in the treated food by any recognized method (viruses being excepted) while no spoilage or toxicity of microbial origin is detectable no matter how long or under what conditions the food is stored in the absence of recontamination.

Type $I I$ is the application to foods of doses of ionizing radiation sufficient to reduce the number of viable specific non-spore-forming pathogenic micro-organisms (other than viruses) so that none is detectable in the treated food by any standard method.

Type III is the application to foods of doses of ionizing radiation sufficient to enhance keeping quality by causing substantial reduction in the numbers of viable specific spoilage micro-organisms.

It will be evident that sterilization by irradiation and Type $I$ treatments have both been indiscriminately covered by the term radiation sterilization, while radiation pasteurization also has covered treatments of both Types $I I$ and $I I I$.

The following are the names we suggest for these types of treatment: Type I, radappertization; Type II, radicida. tion; Type III, radurization; and the reasons for these suggestions are given as follows.

The prefix rad- or radi-stands for the radiation used. (Lat. radiare, to shine). We could not think of any term which would indicate more precisely what kinds of 